\title{
Phomopsols A-B from the Mangrove Endophytic Fungus Phomopsis sp. xy21: Structures, Neuroprotective effects, and Biogenetic Relationships
}

Wan-Shan Li, ${ }^{\dagger}$ Han-Bo Hu, ${ }^{\ddagger}$ Zhong-Hui Huang, ${ }^{\dagger}$ Ren-Jie Yan, ${ }^{\dagger}$ Li-Wen Tian, ${ }^{* \dagger}$ and Jun Wu* ${ }^{* \dagger}$

†School of Pharmaceutical Sciences, Southern Medical University, 1838 Guangzhou Avenue North, Guangzhou 510515, P. R. China

¥Marine Drugs Research Center, College of Pharmacy, Jinan University, 601 Huangpu Avenue West, Guangzhou 510632, P. R. China

*E-mail: Iwtian@smu.edu.cn (L.W.T.)

*E-mail: wwujun2003@yahoo.com (J.W.) 


\title{
Supporting Information-I
}

\author{
${ }^{1} \mathrm{H}$ and ${ }^{13} \mathrm{C}$ NMR spectroscopic data for $1-3$,
} experimental section, and proposed biosynthetic origins of 2-3. 


\section{Table of Contents:}

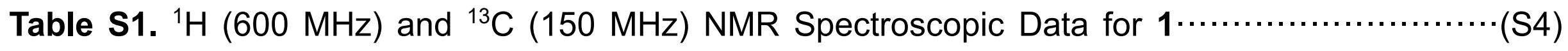

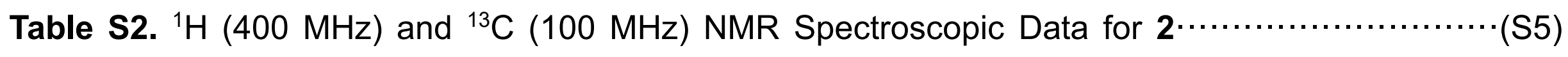

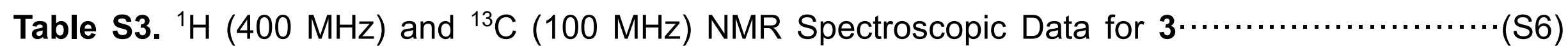

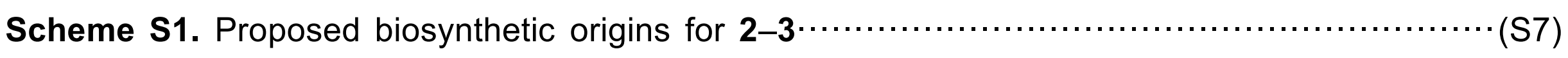

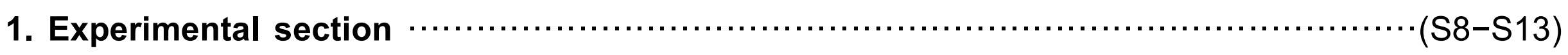

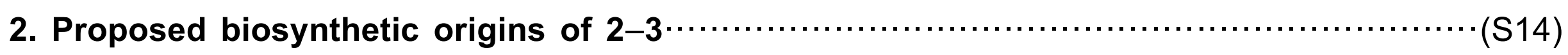


Table S1. ${ }^{1} \mathrm{H}(600 \mathrm{MHz})$ and ${ }^{13} \mathrm{C}(150 \mathrm{MHz})$ NMR spectroscopic data for 1 in methanol- $d_{4}$.

\begin{tabular}{ccc}
\hline No. & $\delta_{\mathbf{H}}(\mathrm{ppm}, J$ in $\mathrm{Hz})$ & $\delta_{\mathrm{c}}(\mathrm{ppm})$ \\
\hline $1,4 \mathrm{a}$ & & $157.2 \mathrm{qC}$ \\
2,4 & $6.40 \mathrm{~d}(7.8)$ & $108.0 \mathrm{CH}$ \\
3 & $7.00 \mathrm{t}(7.8)$ & $130.3 \mathrm{CH}$ \\
5 & $7.68 \mathrm{~s}$ & $120.1 \mathrm{CH}$ \\
6 & & $139.2 \mathrm{qC}$ \\
7 & $6.57 \mathrm{~s}$ & $121.7 \mathrm{CH}$ \\
8 & & $152.2 \mathrm{qC}$ \\
$8 \mathrm{a}$ & & $126.5 \mathrm{qC}$ \\
9 & & $133.7 \mathrm{qC}$ \\
$9 \mathrm{a}$ & & $111.4 \mathrm{qC}$ \\
10 & & $149.0 \mathrm{qC}$ \\
$10 \mathrm{a}$ & & $131.4 \mathrm{qC}$ \\
11 & $2.28 \mathrm{~s}$ & $21.4 \mathrm{CH}_{3}$ \\
$1^{\prime}$ & $4.03 \mathrm{t}(6.0)$ & $61.8 \mathrm{CH}_{2}$ \\
$2^{\prime}$ & $2.13 \mathrm{~m}$ & $25.3 \mathrm{CH}_{2}$ \\
$3^{\prime}$ & $2.42 \mathrm{t}(6.0)$ & $21.4 \mathrm{CH}_{2}$ \\
4 & & $128.1 \mathrm{qC}$ \\
\hline & &
\end{tabular}


Table S2. ${ }^{1} \mathrm{H}(400 \mathrm{MHz})$ and ${ }^{13} \mathrm{C}(100 \mathrm{MHz})$ NMR spectroscopic data for 2 in methanol- $d_{4}$.

\begin{tabular}{ccc}
\hline No. & $\delta_{\mathbf{H}}(\mathrm{ppm}, \mathrm{J}$ in Hz$)$ & $\delta \mathrm{c}(\mathrm{ppm})$ \\
\hline 1 & $6.34 \mathrm{brd}(8.0)$ & $155.7 \mathrm{qC}$ \\
2 & $6.96 \mathrm{t}(8.0)$ & $109.0 \mathrm{CH}$ \\
3 & $6.26 \mathrm{~d}(8.0)$ & $131.5 \mathrm{CH}$ \\
4 & & $107.7 \mathrm{CH}$ \\
$4 \mathrm{a}$ & $4.75 \mathrm{~d}(4.4)$ & $154.8 \mathrm{qC}$ \\
5 & $2.91 \mathrm{~m}$ & $88.3 \mathrm{CH}$ \\
6 & $2.23 \mathrm{~m}$ & $32.0 \mathrm{CH}$ \\
$7 \alpha$ & $2.94 \mathrm{~m}$ & $37.6 \mathrm{CH}$ \\
$7 \beta$ & & $179.4 \mathrm{qC}$ \\
8 & $4.40 \mathrm{~s}$ & $73.7 \mathrm{CH}$ \\
$8 \mathrm{a}$ & $5.15 \mathrm{~s}$ & $75.9 \mathrm{CH}$ \\
9 & & $112.8 \mathrm{qC}$ \\
$9 \mathrm{a}$ & $4.14 \mathrm{~d}(10.4)$ & $76.4 \mathrm{CH}$ \\
$10 \alpha$ & $4.26 \mathrm{~d}(10.4)$ & $89.2 \mathrm{qC}$ \\
$10 \beta$ & & $19.9 \mathrm{CH}_{3}$ \\
$10 \mathrm{a}$ & $1.26 \mathrm{~d}(6.4)$ & \\
11 & & \\
\hline
\end{tabular}


Table S3. ${ }^{1} \mathrm{H}(400 \mathrm{MHz})$ and ${ }^{13} \mathrm{C}(100 \mathrm{MHz})$ NMR spectroscopic data for 3 in methanol- $d_{4}$.

\begin{tabular}{ccc}
\hline No. & $\delta_{\mathbf{H}}(\mathrm{ppm}, \mathrm{J}$ in $\mathrm{Hz})$ & $\delta \mathrm{c}(\mathrm{ppm})$ \\
\hline $1,4 \mathrm{a}$ & & $158.9 \mathrm{qC}$ \\
2,4 & $6.25 \mathrm{br} \mathrm{s}$ & $107.8 \mathrm{CH}$ \\
3 & $6.92 \mathrm{t}(8.4)$ & $131.1 \mathrm{CH}$ \\
5 & $7.11 \mathrm{~s}$ & $116.4 \mathrm{CH}$ \\
6 & & $141.5 \mathrm{qC}$ \\
7 & $6.81 \mathrm{~s}$ & $121.7 \mathrm{CH}$ \\
8 & & $153.3 \mathrm{qC}$ \\
$8 \mathrm{a}$ & & $135.8 \mathrm{qC}$ \\
9 & $6.99 \mathrm{~s}$ & $76.6 \mathrm{CH}$ \\
$9 \mathrm{a}$ & & $109.4 \mathrm{qC}$ \\
10 & & $175.1 \mathrm{qC}$ \\
$10 \mathrm{a}$ & & $130.3 \mathrm{qC}$ \\
11 & $2.36 \mathrm{~s}$ & $21.3 \mathrm{CH}$ \\
\hline
\end{tabular}


Scheme S1. Proposed biosynthetic origins of 2-3.

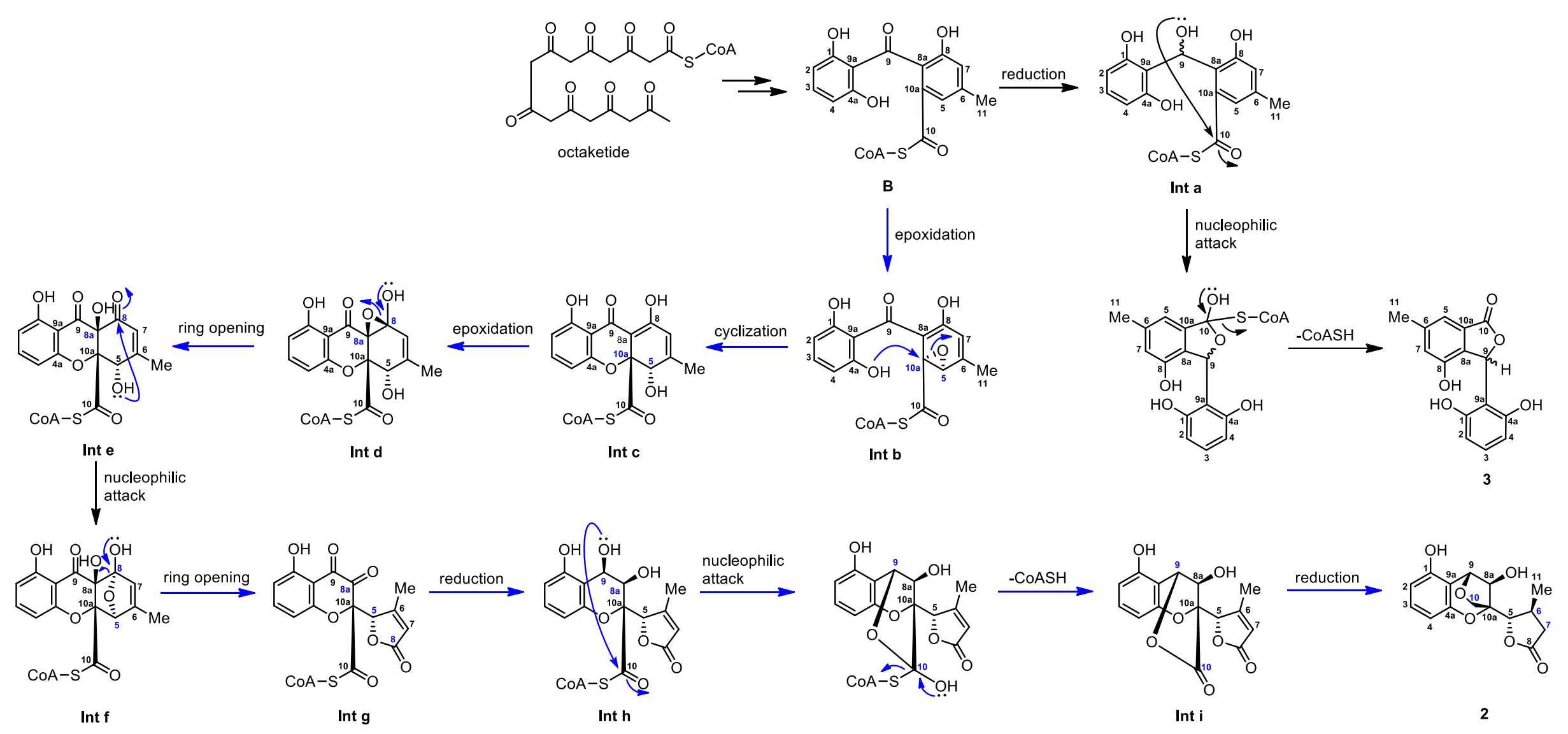




\section{Experimental section}

\subsection{General experimental procedures}

Optical rotations were measured on a MCP 200 digital polarimeter with a microcell of $0.5 \mathrm{~cm}$ path length at $25{ }^{\circ} \mathrm{C}$. UV spectra were recorded on a Thermo GENESYS 10S UV-Vis spectrophotometer. 1D and 2D NMR spectra were measured on a Bruker AVANCE 400 or $600 \mathrm{MHz}$ NMR spectrometer. HRESIMS data were obtained on an Agilent 6210 ESI/TOF mass spectrometer. X-ray crystallographic analyses were carried out on a Rigaku oxford diffractometer, conducted with $\mathrm{Cu}$ Ka radiation $(\lambda=1.54178 \AA$ ). For electronic circular dichroism (ECD) spectra, a Jasco 810 spectropolarimeter (JASCO Corporation, Tokyo, Japan) was applied with the solvent of methanol. Silica gel (200-300 mesh, Qingdao Marine Chemical Inc., Qingdao, China), $\mathrm{C}_{18}$ reversed-phase silica gel (YMC, Kyoto, Japan), and Sephadex LH-20 (Pharmacia Biotech AB, Uppsala, Sweden) were used for column chromatography. High performance liquid chromatography (HPLC) was performed on a Waters 2535 pump equipped with a 2489 UV-Vis detector (Waters, MA, USA) and $\mathrm{C}_{18}$ reversed-phase columns (YMC, Kyoto, Japan; $250 \mathrm{~mm} \times 4.6 \mathrm{~mm}$, length $\times$ i.d., $5 \mu \mathrm{m}$, for analysis; $250 \mathrm{~mm} \times 10 \mathrm{~mm}$, length $\times$ i.d., $5 \mu \mathrm{m}$, for preparation).

\subsection{Fungal material}

Endophytic fungal strain, Phomopsis sp. xy21, was isolated from leaves of the Thai mangrove Xylocarpus granatum collected in Trang Province in February 2012. It was identified as Phomopsis sp. based on sequence 
(GenBank Accession No. KX397026) analysis of the ITS region of the rDNA. The voucher specimen of Phomopsis sp. xy21 was deposited at Marine Drugs Research Center, Jinan University, Guangzhou, P. R. China.

\subsection{Fermentation}

Agar plug (5 mm i.d.) of the fungal strain was inoculated into flasks $(500 \mathrm{~mL})$ containing $200 \mathrm{~mL}$ of potato dextrose broth (PDB; $20 \mathrm{~g}$ glucose and $3 \mathrm{~g}$ sea salt in $1 \mathrm{~L}$ of potato infusion). Flasks with the inoculated fungal strain were incubated on a rotary shaker $(150 \mathrm{rpm})$ at $28^{\circ} \mathrm{C}$ for two days to prepare the seed culture. Large fermentation was performed on solid rice medium in 200 Erlenmeyer flasks ( $50 \mathrm{~g}$ rice, $0.225 \mathrm{~g}$ sea salt, and 75 $\mathrm{mL}$ distilled water per flask, autoclaved at $121^{\circ} \mathrm{C}$ for $25 \mathrm{~min}$ before inoculation). Each flask was inoculated with $1.0 \mathrm{~mL}$ of the spore inoculum and incubated at $28^{\circ} \mathrm{C}$ for 25 days under static conditions.

\subsection{Extraction and isolation}

The fermentation material of Phomopsis sp. xy21 was extracted with methanol at room temperature for five times. The extracted methanol was evaporated under vacuum to yield the resulting extract, which was then extracted with EtOAc $(5 \times 8.0 \mathrm{~L})$ to afford the EtOAc portion $(380.0 \mathrm{~g})$. The EtOAc portion was then fractionated by a silica gel column chromatography $\left(180 \times 10 \mathrm{~cm}\right.$, id) with a gradient mixture of $\mathrm{CHCl}_{3} / \mathrm{MeOH}(100: 0$ to $5: 1)$ to 
give nine fractions (Fr. A-I).

Fr. F (14.6 g) was subjected to a $C_{18}$ reversed-phase column $(60 \times 6 \mathrm{~cm}$, i.d.), eluted with a gradient mixture of $\mathrm{MeOH} / \mathrm{H}_{2} \mathrm{O}$ (10:90 to 100:0) to afford five subfractions (SFr. 1-5). SFr. 2 was further purified by Sephadex LH20 column chromatography with $\mathrm{CHCl}_{3} / \mathrm{MeOH}(1: 1)$ to yield compounds 1 (4.5 mg) and 3 (6.6 mg); whereas SFr. 3 was subjected to the same Sephadex LH-20 column chromatography to give compound 2 (8.0 mg).

\subsubsection{Phomopsol A (1)}

Light red crystal; $[a]_{\mathrm{D}}^{25}+7(c=0.1, \mathrm{MeCN}) ; \mathrm{UV}(\mathrm{MeOH}) \lambda_{\max }(\log \varepsilon) 205$ (4.33), 257 (3.85), 320 (3.78) nm; HRESIMS $\mathrm{m} / \mathrm{z} 322.1088[\mathrm{M}-\mathrm{H}]^{-}$(calcd for $\mathrm{C}_{19} \mathrm{H}_{16} \mathrm{NO}_{4}, 322.1085$ ); ${ }^{1} \mathrm{H}$ and ${ }^{13} \mathrm{C}$ NMR spectroscopic data, see Table S1.

\subsubsection{Phomopsol B (2)}

Colorless crystal; $[a]_{\mathrm{D}}^{25}+60(c=0.1, \mathrm{MeOH}) ; \mathrm{UV}(\mathrm{MeOH}) \lambda_{\max }(\log \varepsilon) 207$ (4.70), 286 (3.50), $311(2.88) \mathrm{nm}$; HRESIMS m/z 291.0875 [M - H ] ] $^{-}$calcd for $\mathrm{C}_{15} \mathrm{H}_{15} \mathrm{O}_{6}, 291.0874$ ); ${ }^{1} \mathrm{H}$ and ${ }^{13} \mathrm{C}$ NMR spectroscopic data, see Table S2.

\subsubsection{Compound 3}

Colorless crystal; $[a]_{\mathrm{D}}^{25} 0(c=0.4, \mathrm{MeOH})$; UV (MeOH) $\lambda_{\max }(\log \varepsilon) 209$ (4.88), 287 (3.77) nm; HRESIMS m/z $271.0610[\mathrm{M}-\mathrm{H}]^{-}$(calcd for $\mathrm{C}_{15} \mathrm{H}_{11} \mathrm{O}_{5}, 271.0612$ ); ${ }^{1} \mathrm{H}$ and ${ }^{13} \mathrm{C}$ NMR spectroscopic data, see Table S3. 


\subsection{X-ray crystallographic data of compounds 1-3}

Phomopsol A (1): The measurement was made on an Agilent Xcalibur Atlas Gemini ultra diffractometer with mirror monochromated Cu-Ka radiation $\left(\lambda=1.54178 \AA\right.$ ) at $100 \mathrm{~K}$. Triclinic, $\mathrm{C}_{19} \mathrm{H}_{17} \mathrm{NO}_{4}$, space group $P-1$ with a $=8.5039(3)$ $\AA, b=11.5239(7) \AA, c=16.7668(6) \AA, V=1577.89(12) \AA^{3}, Z=4, D_{\text {calcd }}=1.361 \mathrm{Mg} / \mathrm{m}^{3}, m=0.778 \mathrm{~mm}^{-1}$ and $F(000)$ $=680$. Crystal size: $0.15 \times 0.13 \times 0.11 \mathrm{~mm}^{3}$. Independent reflections: 6180 with $R_{\text {int }}=0.0318$. The structure was solved by direct methods (SHELXS-97) and refined using full-matrix least-squares difference Fourier techniques. All non-hydrogen atoms were refined anisotropically, and all hydrogen atoms were placed in idealized positions and refined as riding atoms with the relative isotropic parameters. The final agreement factors were $R 1=0.0738$ and $w R 2=0.2130[I>2 \sigma(I)]$.

Phomopsol B (2): The measurement was made on an Agilent Xcalibur Atlas Gemini ultra diffractometer with mirror monochromated Cu-Ka radiation $\left(\lambda=1.54184 \AA\right.$ ) at $100 \mathrm{~K}$. Orthorhombic, $\mathrm{C}_{15} \mathrm{H}_{16} \mathrm{O}_{6}$, space group $P 2{ }_{1} 2{ }_{1}{ }_{2}$ with $a=7.11300(10) \AA, b=11.70750(10) \AA, c=15.95030(10) \AA, V=1328.268(14) \AA^{3}, Z=4, D_{\text {calcd }}=1.462 \mathrm{Mg} / \mathrm{m}^{3}$, $m=0.959 \mathrm{~mm}^{-1}$ and $F(000)=616.0$. Crystal size: $0.14 \times 0.13 \times 0.12 \mathrm{~mm}^{3}$. Independent reflections: 2637 with $R_{\mathrm{int}}$ $=0.0281$. The structure was solved by direct methods (SHELXS-97) and refined using full-matrix least-squares difference Fourier techniques. All non-hydrogen atoms were refined anisotropically, and all hydrogen atoms were placed in idealized positions and refined as riding atoms with the relative isotropic parameters. The final agreement factors were $R 1=0.0268$ and $w R 2=0.0705[I>2 \sigma(I)]$. The absolute structure parameter is $0.00(4)$.

Compound 3: The measurement was made on an Agilent Xcalibur Atlas Gemini ultra diffractometer with mirror 
monochromated Cu-Ka radiation $(\lambda=1.54184 \AA)$ at $293.98 \mathrm{~K}$. Triclinic, $\mathrm{C}_{15} \mathrm{H}_{12} \mathrm{O}_{5}$, space group $P-1$ with $\mathrm{a}=$ 8.0030(8) $\AA, b=8.7060(7) \AA, c=10.8505(8) \AA, V=644.04(10) \AA^{3}, Z=2, D_{\text {calcd }}=1.462 \mathrm{Mg} / \mathrm{m}^{3}, m=0.959 \mathrm{~mm}^{-1}$ and $F(000)=304.0$. Crystal size: $0.11 \times 0.10 \times 0.08 \mathrm{~mm}^{3}$. Independent reflections: 2637 with $R_{\text {int }}=0.0281$. The structure was solved by direct methods (SHELXS-97) and refined using full-matrix least-squares difference Fourier techniques. All non-hydrogen atoms were refined anisotropically, and all hydrogen atoms were placed in idealized positions and refined as riding atoms with the relative isotropic parameters. The final agreement factors were $R 1$ $=0.0369$ and $w R 2=0.0978[I>2 \sigma(l)]$.

CCDC-1903463 (1), 1903464 (2), and 1903465 (3) contain the supplementary crystallographic data for this paper. These data are provided free of charge by The Cambridge Crystallographic Data Centre.

\subsection{Neuroprotective activity assay}

PC12 cells (Shanghai Cell Bank, Chinese Academy of Sciences) were cultured in DMEM medium supplemented with $10 \%$ heat-inactivated horse serum, $5 \%$ fetal bovine serum, penicillin (100 units $/ \mathrm{mL}$ ), and streptomycin $(100 \mu \mathrm{g} / \mathrm{mL})$. Cells were seeded into 96 -well plates at a density of $1 \times 10^{4}$ cells per well and cultured in the medium consisted of $1 \%$ fetal bovine serum (FBS) with $5 \% \mathrm{CO}_{2}$ for $24 \mathrm{~h}$. Compounds dissolved in DMSO $(40 \mathrm{mM})$ as a stock were further diluted by $1 \%$ FBS into four different concentrations $(5,10,20$, and $40 \mu M)$. Then the cell culture medium was replaced by $1 \%$ FBS containing different concentrations of compounds 1-3 for pre- 
incubation for $2 \mathrm{~h}$. Corticosterone with the final concentration of $200 \mu \mathrm{M}$ was added into the culture medium and incubated for $24 \mathrm{~h}$. Thereafter, $20 \mu \mathrm{L}$ of MTT $(5 \mathrm{mg} / \mathrm{mL})$ was added into each well and incubated for an additional $4 \mathrm{~h}$. The supernatant was removed and the formazone crystals were dissolved in $150 \mu \mathrm{L}$ DMSO. The optical absorbance at $570 \mathrm{~nm}$ was read with a multimode microplate reader.
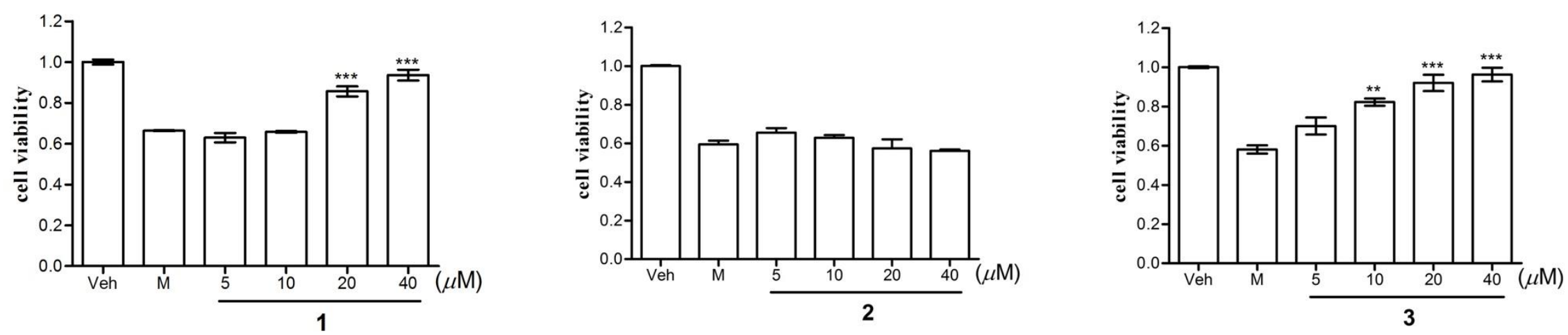

Figure S1. Neuroprotective activity assay of compounds 1-3. M: corticosterone treatment group (model group). Data were Mean \pm SD of three independent experiments. ${ }^{*} p<0.05,{ }^{* *} p<0.01,{ }^{* * *} p<0.001$; significantly different from the model group.

\section{Proposed biosynthetic origins of $2-3$}

Plausible biosynthetic origins for 2-3 are proposed in Scheme S1. The building block B would be the crucial precursor, which could be traced back to eight units of acetyl coenzyme A (ACoA). The reduction at C-9 of B could 
afford the intermediate a (Int a). The nucleophilic attack of the 9-OH group at the C-10 carbonyl function of Int a, and then the elimination of one unit of coenzyme $\mathrm{A}(\mathrm{CoASH})$ would give 3.

The epoxidation of the $\mathrm{C}-5=\mathrm{C}-10 \mathrm{a}$ bond could generate Int $\mathbf{b}$, cyclization of which would produce Int $\mathbf{c}{ }^{1}$ Similarly, the epoxidation of the $\mathrm{C}-8=\mathrm{C}-8 \mathrm{a}$ bond of Int $\mathbf{c}$ could afford Int $\mathbf{d}$. Then the opening of the epoxy ring would yield Int $\mathbf{e}$. The nucleophilic attack of the $5-\mathrm{OH}$ group at the $\mathrm{C}-8$ carbonyl function of Int e could give Int $\mathbf{f}$, ring opening of which would afford Int $\mathbf{g}$. Reduction of Int $\mathbf{g}$ could yield Int $\mathbf{h}$. The nucleophilic attack of the 9-OH

group at the C-10 carbonyl function of Int $\mathbf{h}$, and then the elimination of one unit of coenzyme A (CoASH) would give Int $\mathbf{i}$. Finally, the reduction of the C-6=C-7 bond and the C-10 carbonyl function of Int $\mathbf{i}$ could produce 2.

\section{REFERENCES}

(1) Matsuda, Y.; Gotfredsen, C. H.; Larsen, T. O. Org. Lett. 2018, 20, 7179-7200. 